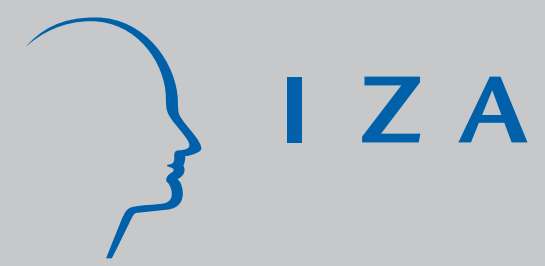

IZA DP No. 4219

The Timing of Maternal Work and Time with Children

Jay Stewart

June 2009

Forschungsinstitut

zur Zukunft der Arbeit

Institute for the Study

of Labor 


\title{
The Timing of Maternal Work and Time with Children
}

\author{
Jay Stewart \\ U.S. Bureau of Labor Statistics \\ and IZA
}

Discussion Paper No. 4219

June 2009

IZA

P.O. Box 7240
53072 Bonn
Germany

Phone: +49-228-3894-0

Fax: +49-228-3894-180

E-mail: iza@iza.org

Any opinions expressed here are those of the author(s) and not those of IZA. Research published in this series may include views on policy, but the institute itself takes no institutional policy positions.

The Institute for the Study of Labor (IZA) in Bonn is a local and virtual international research center and a place of communication between science, politics and business. IZA is an independent nonprofit organization supported by Deutsche Post Foundation. The center is associated with the University of Bonn and offers a stimulating research environment through its international network, workshops and conferences, data service, project support, research visits and doctoral program. IZA engages in (i) original and internationally competitive research in all fields of labor economics, (ii) development of policy concepts, and (iii) dissemination of research results and concepts to the interested public.

IZA Discussion Papers often represent preliminary work and are circulated to encourage discussion. Citation of such a paper should account for its provisional character. A revised version may be available directly from the author. 


\section{ABSTRACT \\ The Timing of Maternal Work and Time with Children}

I use data from the American Time Use Survey to examine how maternal employment affects when during the day that mothers of pre-school-age children spend doing enriching childcare and whether they adjust their schedules to spend time with their children at more-desirable times of day. I find that employed mothers shift enriching childcare time from workdays to nonwork days. On workdays, full-time employed parents shift enriching childcare time toward evenings, but there is little shifting among part-time employed mothers. I find no evidence that full-time employed mothers adjust their schedules to spent time with their children at more-preferred times of day, whereas part-time employed mothers shift employment to later in the day.

JEL Classification: J22, J13

Keywords: $\quad$ timing of activities, time use, childcare

Corresponding author:

Jay Stewart

U.S. Bureau of Labor Statistics

2 Massachusetts Ave., NE

Washington, DC 20212

USA

E-mail: Stewart.Jay@bls.gov

\footnotetext{
* Any views expressed are mine and do not necessarily reflect those of the Bureau of Labor Statistics. I thank Dori Allard, Bob Drago, Harley Frazis, Irina Paley, participants in the IZA Topic Week on Nonmarket Time in Economics, and two anonymous referees for their helpful comments and suggestions.
} 


\section{Introduction}

The effect of maternal employment on child development is a hotly-debated topic. Maternal employment can enhance child development if it results in additional resources being available for enriching types of activities, such as reading to and playing with children. But it can be detrimental if working crowds out childcare time. Sociological studies have shown that maternal employment results in mothers spending less time with their children, but that mothers go to great lengths to reduce the impact on childcare time by cutting back on other activities such as sleep and household work.

Another avenue by which maternal employment might negatively affect child outcomes is through the timing of childcare activities. Psychological research on circadian rhythms suggests that some times of day are likely to better than others for parent-child interactions. Employment may result in parents spending time with their children when that time is less valuable. If this is the case, then we would expect mothers to adjust their schedules so they can spend time with their children at times of day when the benefits from these activities are greater.

In this study, I examine how employment affects the when during the day that mothers spend time with their children in enriching childcare activities. I then look for evidence that mothers adjust their schedules to reduce the impact of employment on the timing of childcare activities. The main focus of this study is on the mothers of pre-school-age children (ages 0-4), because they have more flexibility with respect to the timing of childcare activities than do the mothers of school-age children.

\section{Background}

Several recent studies (Baum 2003, Ruhm 2004, James-Burdumy 2005) have examined the effect of maternal employment on children's cognitive development. The results are 
somewhat mixed, but they generally show that maternal employment has a detrimental effect on child development as measured by scores on standardized tests. ${ }^{1}$ These authors have very little to say about the mechanisms by which this occurs although Rhum (2004) and James-Burdumy (2005) suggest that research on these mechanisms would be useful, with James-Burdumy specifically mentioning time-diary data. The most obvious mechanism is through the amount of time spent in enriching childcare, such as playing with and reading to children.

A number of studies have examined the effect of maternal employment on childcare time, and has found that employed mothers spend less time with their children than nonemployed mothers. ${ }^{2}$ And a recent study by Cawley and Liu (2007) focused on the effect of maternal employment on time spent in education-related activities and found that employed mothers spend less time reading to their children and helping them with their homework, as well as less time playing with children. But there has been almost no research on when this care is provided. ${ }^{3}$

The timing of childcare matters because not all time is equally valuable. Time spent in enriching childcare activities is likely to be more beneficial for the children and more enjoyable for their mothers at times when the children are more receptive to learning and their mothers are not tired. If it is the amount of quality-adjusted time with children that matters and employment causes their mothers to shift enriching childcare to "less-productive” times of day, then looking only at the amount of time in enriching childcare understates the full impact of employment on maternal time with children.

\footnotetext{
${ }^{1}$ Baum (2003) and Ruhm (2004) find that maternal employment has negative effects on test scores, while JamesBurdumy (2005) finds both negative and positive effects depending on the age of the child when the mother worked.

${ }^{2}$ For example, see Bianchi $(2000,2006)$ and Bianchi, Robinson, and Milkie (2006).

${ }^{3}$ Craig (2006) presents some evidence that employed mothers are less likely to spend time with their children in the morning and the afternoon.
} 
The large body of research on circadian rhythms examines how biological functions vary over the course of the day. ${ }^{4}$ One facet of this research focuses on individuals' preferences for certain times of day, with individuals being classified as preferring either mornings or evenings. These studies are based on the Morningness-Eveningness Questionnaire (MEQ), which is designed to assess subjects' preferences. ${ }^{5}$ Most of the research has focused on teenagers and adults. Teens and younger adults generally prefer afternoons and evenings, while older adults tend to prefer mornings. Other studies have shown that performance on complex tasks is better at preferred times of day, whereas performance on routine tasks is invariant to the time of day.

There is less research available on the time-of-day preferences of young children. Two studies have examined the morningness/eveningness of 8-16 year olds (Kim, et al 2002) and 2-6 year olds (Wickersham 2006). ${ }^{6}$ The Kim, et al study found that younger children prefer the mornings, while older children prefer afternoons and evenings. The crossover point for this change is at about age 13. The Wickersham study found that pre-school-age children prefer mornings, and that the preference is quite strong in two- and three-year-olds. If young children also perform better on complex tasks at their preferred time of day then we might expect enriching care to be more valuable, and thus more "productive," in the morning than in the evening, with the afternoon falling somewhere between the two.

The key points to take away from this research are that it matters when during the day that parents spend time with their children and that children generally prefer times of day that coincide with normal work hours. The times of day that parents actually choose to spend time

\footnotetext{
${ }^{4}$ This discussion is based on Hasher, Goldstein, and May (2005), which contains a nice summary of the relevant research on this topic.

${ }^{5}$ The MEQ asks respondents about preferred times for doing certain types of activities, as well as preferred times for waking up and going to sleep.

${ }^{6}$ In the Wickersham study, the MEQ was adapted so that parents could answer for their children.
} 
with their children will depend on their own time-of-day preferences, their children’s

preferences, and the productivity of time spent in other activities at different times of day.

\section{A Simple Model of Timing}

To see how differences in the productivity of time spent in childcare and other activities over the course of the day affect the timing of those activities, consider a simple two-stage model of timing. ${ }^{7}$ In the first stage, mothers maximize utility and determine the optimal amount of time to spend in each activity during a given period of time, such as a day. ${ }^{8}$ In the second stage, they determine how that time is distributed over the sub-periods within the day. ${ }^{9}$ For simplicity, I assume that there are two sub-periods and two activities.

In the first stage, mothers receive utility from time spent in enriching childcare, $A$, and all other activities, $X$, which include leisure, household work, and working for pay. ${ }^{10}$ The productivity of time spent in each of these activities is given by the functions $\Gamma(\gamma)$ for activity $A$ and $\Theta(\boldsymbol{\theta})$ for $X$, where the arguments $\gamma$ and $\boldsymbol{\theta}$ are vectors of productivities for the sub-periods and $\Gamma_{i}, \Theta_{i}>0$ for $i=1,2$. Each mother solves the following first-stage optimization program:

$$
\operatorname{Max}_{A, X} U(\Gamma(\gamma) A, \Theta(\boldsymbol{\theta}) X) \quad \text { s.t. } A+X=2 T,
$$

\footnotetext{
${ }^{7}$ There is relatively little research on the timing of activities. An early paper by Winston (1982) presents a theoretical model of timing. Two other studies examine the timing of work activities (Hamermesh, Knowles, and Pocock 2006) and the coordination of husbands' and wives' time with children (Paley 2006). Hamermesh (2005) and Hamermesh and Donald (2007) examine the effect of employment on the timing of other activities. Hamermesh (2002) and van Klaveren and van den Brink (2007) examine the synchronization of husbands' and wives' work schedules. My theoretical model is most similar to the one in Conolly (2008), who examines the effect of weather on the timing of work and leisure activities.

${ }^{8}$ I do not model the joint decision-making of mothers and fathers. The model is intended mainly to show how timeof-day preferences affect the timing of work and enriching childcare and to help guide the empirical work.

${ }^{9}$ Technically, it would be more realistic to solve the utility maximization problem in one stage with the time spent in each activity at each time as an argument in the utility function. But it is easier to see the intuition in the two-stage model.

${ }^{10}$ The utility from $\mathrm{X}$ therefore includes utility derived from goods purchased from labor market earnings as well as the utility of leisure and the utility derived from household production. A more traditional model that includes market work and leisure as separate activities, includes consumption of market goods, and explicitly models household production would be more complicated but the important results would not change.
} 
where $\mathrm{T}$ is the total amount of time in each sub-period. The solution to this program is straightforward and the optimal values of $A$ and $X$ will be denoted as $A^{*}$ and $X^{*}$.

The second stage maximization program can be written as:

$$
\begin{gathered}
\operatorname{Max} u=\gamma_{1} f\left(a_{1}\right)+\gamma_{2} f\left(a_{2}\right)+\theta_{1} g\left(x_{1}\right)+\theta_{2} g\left(x_{2}\right) \\
\text { s.t. } \quad a_{1}+a_{2}=A^{*} \\
x_{1}+x_{2}=X^{*} \\
a_{1}+x_{1}=T \\
a_{2}+x_{2}=T
\end{gathered}
$$

where $a_{i}$ and $x_{i}$ denote the time spent in childcare and in other activities in sub-period $i, f^{\prime}, g^{\prime}>0$, and $f^{\prime \prime}, g^{\prime \prime}<0$. The equilibrium condition for this program is:

$$
\gamma_{1} f^{\prime}\left(a_{1}\right)-\theta_{1} g^{\prime}\left(T-a_{1}\right)=\gamma_{2} f^{\prime}\left(a_{2}\right)-\theta_{2} g^{\prime}\left(T-a_{2}\right)
$$

Thus parents equate the difference between the marginal utilities of the two activities across the two sub-periods, where the difference is equal to the difference between the lagrangian multipliers on the two constraints. ${ }^{11}$ This condition along with the assumptions regarding the functional forms of $f(\cdot)$ and $g(\cdot)$ guarantee that, all else equal, parents will spend more time with their children when that time is more productive. More generally, an increase in the productivity of $A$ in sub-period $1, \gamma_{1}$, affects $a_{1}$, and hence $a_{2}$, directly though changes in the relative productivities of $A$ and $X$ in sub-periods 1 and 2, and indirectly through changes in $A^{*}$ and $X^{*}$. The former effect is akin to a substitution effect, while the latter is akin to a scale effect.

The substitution effect can be seen by holding $A^{*}$ (and $X^{*}$ ) constant and totally differentiating the second-stage equilibrium condition in equation (1) with respect to $\gamma_{1}$ using the implicit function rule, yielding the following:

\footnotetext{
${ }^{11}$ The inequality of the marginal products is an artifact of the two-stage optimization program and the adding-up constraint in the second stage.
} 


$$
\left.\frac{d a_{1}^{*}}{d \gamma_{1}}\right|_{d A^{*}=0}=\frac{-f^{\prime}\left(a_{1}^{*}\right)}{\gamma_{1} f^{\prime \prime}\left(a_{1}^{*}\right)+\theta_{1} g^{\prime \prime}\left(x_{1}^{*}\right)+\gamma_{2} f^{\prime \prime}\left(a_{2}^{*}\right)+\theta_{2} g^{\prime \prime}\left(x_{2}^{*}\right)}>0 .
$$

Similarly,

$$
\left.\frac{d a_{1}^{*}}{d \theta_{1}}\right|_{d A^{*}=0}=\frac{-g^{\prime}\left(x_{1}^{*}\right)}{\gamma_{1} f^{\prime \prime}\left(a_{1}^{*}\right)+\theta_{1} g^{\prime \prime}\left(x_{1}^{*}\right)+\gamma_{2} f^{\prime \prime}\left(a_{2}^{*}\right)+\theta_{2} g^{\prime \prime}\left(x_{2}^{*}\right)}<0 .
$$

Thus an increase in the productivity of activity $A$ in sub-period 1 causes parents to shift time in activity $A$ from sub-period 2 to sub-period 1 , while an increase in the productivity of activity $X$ in sub-period 1 results in a shift in the opposite direction (holding $A^{*}$ and $X^{*}$ constant). ${ }^{12}$ The adding-up constraint implies that:

$$
\left.\frac{d x_{1}^{*}}{d \theta_{1}}\right|_{d X^{*}=0}>0 \text { and }\left.\frac{d x_{1}^{*}}{d \gamma_{1}}\right|_{d X^{*}=0}<0
$$

The sign of the scale effect is ambiguous. Differentiating the first-stage equilibrium condition and arranging terms yields:

$$
\frac{d A^{*}}{d \gamma_{1}}=\frac{-\Gamma_{1}(\gamma) A^{*} \cdot\left(\delta_{U_{1}, \Gamma A}-\frac{A^{*}}{X^{*}} \delta_{U_{1}, \Theta X}+1\right)}{\Gamma(\gamma) \cdot\left(\delta_{U_{1}, \Gamma A}-\frac{A^{*}}{X^{*}} \delta_{U_{1}, \Theta X}\right)} \gtreqless 0,
$$

where $\delta_{U_{1}, \Gamma A}<0$ is the own elasticity of marginal utility with respect to quality-adjusted time in $A$ (which equals $\Gamma \cdot A$ ) and $\delta_{U_{1}, \Theta X}$ is the elasticity with respect to quality-adjusted time in $X$

\footnotetext{
${ }^{12}$ If the daily production function is specified as $f\left(\gamma_{1} a_{1}\right)$ instead of $\gamma_{1} f\left(a_{1}\right)$, then $d a_{1}^{*} / d \gamma_{1}$ is positive as long as the elasticity of marginal product with respect to quality-adjusted time is greater than -1 . If the marginal product function is elastic, then the amount of quality-adjusted time increases, but actual time decreases. The result in equation (2) also depends on the assumption that utility in the second stage is additively separable across activities and time periods. However, this assumption seems reasonable over short period of time such as a day or so.
} 
(which equals $\Theta \cdot X$ ). If $-1<\left(\delta_{U_{1}, \Gamma A}-\frac{A^{*}}{X^{*}} \delta_{U_{1}, \Theta X}\right)<0$ then $\frac{d A^{*}}{d \gamma_{1}}>0$. If $A^{*}$ is small relative to $X^{*}$, as would be the case for enriching childcare activities, then $\frac{d A^{*}}{d \gamma_{1}}>0$ if $-1<\delta_{U_{1}, \Gamma A}<0$.

\section{Implications}

Although I did not explicitly model multiple days above, I can still shed light on workday-nonwork-day comparisons. Suppose that the productivity of enriching childcare is higher in sub-period 1 (daytime) than in sub-period 2 (evening) and that productivity does not depend on whether the day is a workday- $\gamma_{1}^{N}=\gamma_{1}^{W}>\gamma_{2}^{N}=\gamma_{2}^{W}$, where the $W$ and $N$ superscripts denote workdays and nonwork days. Now suppose that other activities are assumed to have either: (1) the same productivity in both sub-periods on nonwork days and higher productivity in sub-period $1\left(\theta_{1}^{W}>\theta_{1}^{N}=\theta_{2}^{N}=\theta_{2}^{W}\right)$ on workdays, or (2) higher productivity in both sub-periods $\left(\theta_{1}^{W}=\theta_{2}^{W}>\theta_{1}^{N}=\theta_{2}^{N}\right)$ on workdays. ${ }^{13}$ Higher productivity of other activities in sub-period 1 could reflect the higher productivity of work during normal work hours due to the coordination of work activities (see Hamermesh, Knowles, and Pocock 2006). Equal productivities in both periods could reflect employers' coverage requirements, which might be the case for nurses or retail workers.

In both cases, we would expect to see parents shifting enriching childcare time from workdays to nonwork days. On nonwork days, we would expect them to spend time with their children mostly in sub-period 1 and shift other activities to sub-period 2. The timing of work and childcare on workdays depends on when work time is more productive. We would expect to see parents spend relatively more time working (and less time doing enriching childcare) in sub-

\footnotetext{
${ }^{13}$ I am defining workdays as days in which the relative productivity of work is high enough that the parent chooses to work.
} 
period 1 if the productivity of other (work) activities is higher in sub-period 1 and relatively more in sub-period 2 if the productivity of other activities is the same in both periods.

It is important to note that I have not explicitly modeled the mother's choice of jobs. That choice will depend on their productivity (wage) in different jobs, other sources of income (especially spouse's income), and the strength of preferences for spending time with children during the day. Regarding the latter, we might expect mothers who have a preference for spending time with their children during the evening to work at jobs where sub-period-1 productivity is higher, while mothers who prefer to spend time with their children during the day might be more likely to work at jobs where productivity is independent of time of day.

\section{Data}

I use pooled 2003-2007 data from the American Time Use Survey (ATUS). The ATUS is a time-diary survey that asks respondents to sequentially describe their activities, which are translated into over 400 detailed activity codes, during a 24-hour period. ${ }^{14}$ For each episode, the ATUS also collects the start and stop times, who else was present, and where the respondent was. The ATUS also contains demographic information for all household members and labor force information (including labor force status and usual hours worked) for the respondent and the respondent's spouse or unmarried partner. ${ }^{15}$

I restricted my sample to married women age 18 and older, and defined four sub-samples: mothers of children ages 0-4, mothers of children ages 5-9, mothers of children age 10-17, and

\footnotetext{
${ }^{14}$ If respondents report doing more than one thing at one time (such as cooking while talking to a child), only the activity reported as the primary (or "main") activity is coded. However, traveling--even when done in conjunction with another activity, such as feeding a child--is always considered the primary activity. The diary day starts at 4am "yesterday" and ends at 4am "today."

${ }^{15}$ For additional details about the ATUS, please see Hamermesh, Frazis, and Stewart (2005) and Frazis and Stewart (2007).
} 
women who are not parents. ${ }^{16}$ To facilitate comparisons, I excluded mothers who had children in more than one age category. Thus the main differences between three sub-samples of mothers are the ages of the children (and the mothers), and I interpret any differences in the timing of activities to be due to these age differences. ${ }^{17}$

For my analysis I defined three broad categories of childcare—routine care (such as feeding or bathing), enriching care (such as reading to or playing with children), and other childcare (such as dropping off and picking up children)—using the twenty-six activity codes that describe care of household children. For enriching care activities, I only included time when a child was present. ${ }^{18}$ One complication that arises when comparing time spent in enriching childcare for children of different ages is that activities that might be classified as childcare when a child is young may not be when the child is older. For example, riding bikes with a 3 year-old may be coded as childcare (030105), while riding bikes with a 9 year-old may be coded as bike riding (130104). Since I compare time spent in enriching childcare for mothers with children of different ages, my definition of enriching childcare also includes selected leisure activities that were done while a child was present. The main leisure activity that I excluded is television watching. ${ }^{19}$ (See the Appendix for detailed definitions.)

Table 1 shows the average number of hours per day spent in childcare activities by employment status. Comparing the "all days" columns we can see that, except for "other childcare,” nonemployed mothers spend the most time in childcare, while full-time employed mothers spend the least. Nearly half of childcare done by mothers of 0-4 year-old children is

\footnotetext{
${ }^{16}$ Here, "children” refer to own children (including adopted and step children) who live with their mothers.

${ }^{17}$ The differences could also be due to cohort effects.

${ }^{18}$ I make this restriction because some activities, such as reviewing homework or preparing for a project, can be done when the child is not present.

${ }^{19}$ One leisure activity that is potentially problematic is socializing when other adults are present, because it is possible that the children have been "dragged along" and are not part of the activity. I reran the analysis using an alternative definition of socializing and excluding it altogether, and the results were nearly identical.
} 
routine, while routine childcare accounts for less than one-third of childcare done by mothers of 5-9 year-olds. Mothers of older children (10-17) spend very little time in routine childcare, and time spent in enriching childcare is mostly leisure activities done with these children.

\section{Childcare on Workdays and Nonwork Days}

Table 1 also shows how employed mothers shift childcare from workdays to nonwork days. Workdays are days on which the mother spends any time working at a location other than her home. ${ }^{20}$ It is also important to note that, because the ATUS collects data for only one day, I do not directly observe the shifting of childcare activities. Instead, I compare employed mothers on workdays and nonwork days, noting that whether a mother is observed on any particular day is determined randomly through the procedure for assigning respondents to days of the week. ${ }^{21}$

Overall, employed mothers of 0-4 year-old children spend about 60 percent more time per day doing childcare on nonwork days than they do on workdays, but there are notable differences between full- and part-time employed mothers and by type of childcare. Part-time employed mothers spend about 35 percent more time in routine childcare on nonwork days than on workdays, whereas full-time employed mothers spend 60 percent more. For both full- and part-time employed mothers, enriching childcare is shifted from workdays to nonwork days to a much greater degree than is routine care. This is as we would expect because many routine childcare activities, such as feeding and dressing, must be done every day. Childcare time is shifted in the other direction for "other childcare," which includes transporting children. Fulltime employed mothers spend considerably more time in other childcare activities on workdays than on nonwork days, which likely reflects time spent getting children to and from daycare or

\footnotetext{
${ }^{20}$ The small number of days that mothers work exclusively at home are included with nonwork days because mothers who work at home have considerable flexibility with regard to when they spend time with their children.

${ }^{21}$ The key thing is that the probability that a given day is selected for an interview is independent of the activities that are done on that day.
} 
preschool. In contrast, part-time employed mothers spend an equal amount of time on work and nonwork days.

Looking at the panels for mothers of older children (5-9 year-olds and 10-17 year-olds) we can see that time spent in both routine and enriching childcare decline as the children get older, with the decline being much larger for routine care. As with the mothers of pre-school-age children, childcare is shifted from workdays to nonwork days. Again, enriching childcare is shifted to a much greater degree compared to routine care.

These findings are consistent with the prediction that parents will shift childcare time from workdays to nonwork days. They are also consistent with results in Hamermesh and Donald (2007), who find that the fixed costs associated with working affect the timing of nonwork activities, and Stafford and Yeung (2005), who find that children spend more time with their parents on weekend days than on weekdays.

\section{The Timing of Childcare}

I now turn to the question of when during the day mothers spend time in enriching childcare. The research on circadian rhythms suggests that mornings may be the best time (from the child's perspective) for enriching care. However, because it is the mother's utility that is being maximized and productivity depends on both mother’s and children’s time-of-day preferences, it is possible that mornings are not the most productive time of day. Although I have no direct information on these preferences I can infer when parents prefer to engage in enriching childcare by looking at nonemployed mothers and employed mothers on their nonwork days, when they are not constrained by work schedules. ${ }^{22}$ Thus, I will determine whether

\footnotetext{
${ }^{22}$ Comparing nonemployed mothers to employed mothers is potentially problematic because the employment decision may be related to unobserved differences in time-of-day preferences. For example, mothers who prefer to
} 
employment affects the timing of enriching care by comparing workdays to nonwork days of employed mothers and to all days of nonemployed mothers. If there is no employment effect on timing then, apart from differences in the amount of time spent with children, the distribution of time spent in enriching childcare over the course of a day should be the same on both work and nonwork days.

Figure 1 shows the distribution of enriching childcare time for mothers of 0-4 year-old children on workdays and nonwork days by employment status. The height of each bar is the fraction of total enriching childcare time that is done during that hour. For example, 22 percent of the time that full-time employed mothers spend on enriching childcare on workdays is done between 7:00pm and 8:00pm.

The graphs for all days of nonemployed mothers and for nonwork days of employed mothers are strikingly similar, with the time spent in enriching childcare being distributed fairly uniformly throughout the day. About 40-48 percent of enriching childcare is done between 9:00am and 4:00pm, while 16-20 percent is done between 7:00pm and 10:00pm. The fact that enriching childcare is fairly evenly distributed over the day seems to contradict the circadianrhythm research. But, it is important to keep in mind that both the children's and their mothers' time-of-day preferences come into play here. The distributions of enriching childcare time suggest that, in terms of the theoretical model, $\gamma_{1}$ and $\gamma_{2}$ are not that different from each other. This, along with the assumption that $f(\cdot)$ exhibits diminishing marginal productivity, implies that the total value of enriching childcare is maximized when mothers spend about the same amount of enriching childcare time in each sub-period 
The distribution of enriching childcare time done on workdays by full-time employed mothers is quite different from that on nonwork days, with much of the time on workdays concentrated in the evenings. Over 40 percent of enriching childcare is done between 7:00pm and 10:00pm, while only 15 percent is done between 9:00am and 4:00pm. The distribution of enriching childcare done by part-time employed mothers on workdays lies between these two extremes, but looks more like the nonwork day distributions. Forty percent of enriching childcare is done between 9:00am and 4:00pm, and 27 percent is done between 7:00pm and 10:00pm.

To quantify the differences in the distributions and the amount by which workday distributions diverge from nonwork day distributions, I used a dissimilarity index to compare average workdays and nonwork days. For each pairwise comparison, the weighted absolutedeviation index, $T_{W A D}$, is given by:

$$
T_{W A D}=\sum_{h=1}^{24}\left(\frac{\left|a_{h}-b_{h}\right|}{\left(a_{h}+b_{h}\right)} \times \frac{\left(a_{h}+b_{h}\right)}{\sum_{h=1}^{24} a_{h}+\sum_{h=1}^{24} b_{h}}\right)=\sum_{h=1}^{24}\left(\frac{\left|a_{h}-b_{h}\right|}{2}\right),
$$

where $a_{h}, b_{h}$ are the fractions of time spent in enriching childcare in each hour of the day on days $a$ and $b$, and $a$ and $b$ refer to groups defined by their workday and employment status. The index ranges in value from 0 to 1 , where 0 indicates that the distributions are identical and 1 indicates that there are no times of day in common. ${ }^{23}$

This index has a natural interpretation. It is equal to the fraction of enriching childcare time that one group must reallocate to different times of day in order to make their two

\footnotetext{
${ }^{23}$ The index is designed to measure between-group differences in time spent in all activities (for example, measuring how differently men and women use their time). In my analysis, the groups are defined by employment status and whether or not the day was a workday (for example, comparing work and nonwork days for full-time employed or comparing nonwork days of full-time employed and nonemployed). And the activities are defined by time of day, where time spent in enriching childcare at each hour of the day is viewed as a separate activity. See Stewart (2006) for more details about the index.
} 
distributions identical. Thus, the index values for workday-nonwork day comparisons equal the fraction of enriching childcare time that mothers shift due to market work.

The index values for pairwise comparisons of the three nonwork days (full-time employed, part-time employed, and nonemployed) are all less than 0.10 , which indicates quite a bit of similarity (see Table 2). This is strong evidence that employed mothers have the same time-of-day preferences for enriching childcare as nonemployed mothers, and that the shifting of enriching childcare time from workdays to nonwork days does not affect the timing of these activities on nonwork days. As expected, we see large differences when comparing the workdays of full-time employed mothers to nonwork days (the index values are in the $0.34-0.40$ range). The index values for comparisons to the workdays of part-time employed mothers confirm our earlier observation that the workdays of part-time employed mothers are much closer to nonwork days than they are to the workdays of full-time employed mothers. The index values for comparisons to nonwork days are in the $0.14-0.18$ range. The index of 0.32 for the workday-to-workday comparison of full- and part-time employed mothers is about the same magnitude as the index value for workday-to-nonwork-day comparison for full-time employed mothers. Another way to quantify these differences is to compute the amount of time that would have to be rescheduled. Using the average day of a nonemployed mother as a common reference, full-time employed mothers would have to reschedule about 16 minutes per workday (or about 71 minutes per week) of enriching childcare time compared to 11 minutes per workday (30 minutes per week) for part-time employed mothers. ${ }^{24}$

To summarize, the results in Table 1 show that full-time employed mothers shift enriching childcare time from workdays to nonwork days, while Figure 1 and Table 2 show that

\footnotetext{
${ }^{24}$ Full-time employed mothers of 0-4 year olds work 4.5 days per week on average, while part-time employed mothers work 2.8 days per week.)
} 
they shift enriching childcare time to later times of day on workdays. This shifting reduces the value of enriching childcare time not because the productivity parameter $(\gamma)$ is lower in the evening, but because the enriching childcare production function exhibits diminishing marginal productivity and the total value of enriching childcare time is maximized when enriching childcare time is distributed evenly throughout the day. Part-time employed mothers also shift enriching childcare time from workdays to nonwork days, but on workdays there is very little shifting to later times of the day. Given mothers' preferences for spreading enriching childcare time evenly throughout the day, it would be reasonable to expect them to adjust their work schedules so that they can spend more time with their children at preferred times of day.

\section{The Timing of Work}

To examine how time-of-day preferences affect when during the day that mothers of 0-4 year olds choose to work, I would like to know when these mothers would work if the children were not present. Since I cannot make this comparison, I instead compare the employed mothers of 0-4 year olds to the employed mothers of 5-9 year olds, 10-17 year olds and employed women who are not mothers.

The most appropriate control group would appear to be the mothers of 5-9 year-old children. These mothers spend almost as much time in enriching childcare activities as mothers of 0-4 year-old children and are likely to have the same characteristics, except that they are on average 5 years older. Perhaps more importantly, the distribution of time spent in enriching childcare activities by these mothers on nonwork days is similar to mothers of 0-4 year-olds (see Figure 2). Like the mothers of 0-4 year olds, $41-48$ percent of these mothers' enriching childcare is done between 9:00am and 4:00pm. The main difference is that mothers of 5-9 year olds do less enriching childcare between 9:00am and noon and more between noon and 4:00pm. Thus 
the time-of-day preferences of mothers of 5-9 year olds are fairly similar to those of mothers of 0-4 year olds.

The key difference between mothers of 5-9 year-olds and the mothers of 0-4 year olds is that the mothers of 5-9 year olds cannot spend time with their children when the children are in school. In the context of the theoretical model, this implies that $\gamma_{1}$ is close to zero on school days and that these mothers will spend very little time in enriching childcare activities at these times of day. We can see in Figure 2 that both part-time and full-time employed mothers of 5-9 year olds spend very little time in enriching childcare activities on workdays, which are mostly school days. ${ }^{25}$ However, the low productivity of enriching childcare time during school hours also implies that employed mothers will shift their work schedule so that they work more in the morning and early afternoon. This also implies that comparing the mothers of 0-4 year olds to the mothers of 5-9 year olds will overstate the extent to which the former adjust their schedules to spend time with their children. For this reason, I also compare the mothers of 0-4 year olds to the mothers of 10-17 year olds and to women who are not parents. ${ }^{26}$

There is potentially a similar problem with the mothers of 10-17 year-old children. Again, the productivity of mothers' enriching childcare time is close to zero when their children are in school, which would lead to mothers shifting work to earlier in the day. On the other hand, these older children are more independent and it is less critical that a parent be home when these older children come home from school. Moreover, these older children prefer later times of day (although they may not want to spend that time with their parents).

\footnotetext{
${ }^{25}$ Ideally, I would also like to distinguish between school and non-school days. But the sample is not large enough to do so. In the regression analysis, I control for whether the diary day is a school day.

${ }^{26}$ Another factor that facilitates mothers' labor force participation is the availability of before- and after-school day care (also known as extended day) that allow parents to drop children off at school before the school day begins or to stay at school after the official school day has ended. In 2007 nearly half of all elementary schools offered these programs (Snyder, Dillow, and Hoffman 2008, Table 97).
} 
My final comparison is to women who are not parents. I believe that these women are the most appropriate control group because their time-of-day preferences for work are not influenced by school considerations but instead are likely determined by their desire to spend time with their husbands. Studies by Hamermesh (2002) and van Klaveren and van den Brink (2007) support this supposition. Both studies found that married couples synchronize their work schedules so that they can spend more time together, but they synchronize to a lesser extent when there are children present.

For each of these comparisons, I estimated a series of linear probability models. I restricted my sample to workdays and estimated a separate linear probability model for each time of day between 6:00am and 11:00pm at 5-minute intervals (204 equations total). The dependent variable equals one if the parent was working away from home at that moment, and the independent variable of interest is a dummy variable that equals one if the women was the mother of a 0-4 year old. I controlled for the mother's age and education; her husband's employment status and education; whether the diary day was in the summer, a school day, or a weekend; and the amount of time spent working away from home on the diary day. ${ }^{27}$

Figures 3 and 4 graph the coefficients on the dummy variables for the presence of $0-4$ year-old children (and no older children) by time of day. Comparisons to each control group are shown in separate panels. I constructed 95-percent confidence intervals using robust standard errors clustered by geographic identifiers (not shown), and found that most of the individual coefficients are not statistically significant. But the significance of individual coefficients is less important than whether the difference is statistically significant for blocks of time. To perform

\footnotetext{
${ }^{27}$ School days are defined as non-holiday weekdays between September $15^{\text {th }}$ and December $15^{\text {th }}$ or between January $15^{\text {th }}$ and May $15^{\text {th }}$. A day is considered a school day only if school-age children live in the household. Summer is the period from June $1^{\text {st }}$ through August $31^{\text {st }}$. The school-day variable was not included in the equation comparing mothers of 0-4 year olds to non-parents.
} 
these tests, I ran three regressions for every possible 30-minute block of time between 6:00am and 11:00pm. The first block of regressions were run for 6:00am, 6:15am, and 6:30am, the second block for 6:05am, 6:20am, and 6:35am, and so on. The three equations for each block were estimated jointly to properly account for the cross-equation correlation of residuals and to facilitate the hypothesis testing. For each block, I tested whether the sum of the three coefficients was significantly greater than or less than zero (depending on time of day) using a one-tailed test that accounts for clustering as above. ${ }^{28}$ Times for which the sum of the three coefficients are statistically significant are indicated by the bold portions of the graph.

Figure 3 shows the coefficients for full-time employed mothers of 0-4 year olds. The smallest coefficients are for the comparison to mothers of 5-9 year olds, with the difference being larger than 0.05 in absolute value at only a few times during the day. There are larger differences in the middle panel's comparison to mothers of 10-17 year-old children, with the differences being largest in the early morning and late afternoon. Even so, the coefficient never exceeds 0.1 in absolute value. The largest differences are in the bottom-panel comparison to non-parents. Mothers of 0-4 year olds are 5-10 percentage points more likely to work at earlyafternoon times and 5-10 percentage points less likely to work in the early evening. This likely reflects these mothers' desire to be home at dinnertime. Even though the differences are statistically significant for several blocks of time in the mornings and evenings, they are small given that, between 8:00am and 4:00pm, an average of 73 percent of full-time employed women are working at any given time. Thus it is clear is that even though full-time employed mothers have the same time-of-day preferences as part-time employed and nonemployed mothers regarding when they do enriching childcare, it is too costly for them to make large adjustments to their work schedules so that they can spend more time with their children earlier in the day. The

\footnotetext{
${ }^{28}$ The tests were run using STATA’s suest command, which allows for clustering.
} 
lack of variability of work schedules by presence and age of children among full-time employed mothers is consistent with the result in Hamermesh (2005) that the presence of children has no effect on "temporal variety"—variability in the timing of activities.

Figure 4 shows the same comparisons for part-time employed women. Here we see much larger differences. The top graph indicates that, compared to the mothers of 5-9 year-old children, the mothers of 0-4 year olds are less likely to be working during school hours and more likely to be working outside of school hours. This is consistent with the prediction from the theoretical model that mothers of school-age children will shift work to times when their children are in school. The differences are quite large in the mid-morning, with mothers of 0-4 year olds being 10-30 percentage points less likely to be working. They are also about 15 percentage points less likely to be working during the early afternoon. These differences are statistically significant for about three hours in the mid-morning and just under an hour in the afternoon. These mothers are 10-15 percentage points more likely to be working in the early morning and 15-20 percentage points more likely in the early evening. The morning and evening differences are statistically significant for blocks of time that are approximately one and three hours long. As noted above, these estimates are likely overestimates of the true effect because of the shifting of work to school hours by the mothers of 5-9 year olds.

The differences are smaller when comparing the mothers of 0-4 year olds to the mothers of 10-17 year olds, but they are still large. The differences are in the 10 percentage-point range in the morning, the 10-15 percentage-point range in the early afternoon, and the 10 percentagepoint range in the evening, with a smaller fraction of mothers of 0-4 year olds working in the morning and afternoon. Given that an average of about 55 percent of part-time employed nonparent women work at any given time between 8:00am and 4:00pm, a 10-15 percentage point 
difference translates to an 18-27 percent difference. The period over which the differences are statistically significant cover about two hours in the morning and afternoon and about one hour in the evening.

The bottom panel of Figure 4 shows the comparison to women who are not parents, which I have argued is the most appropriate control group. Here the differences are somewhat smaller than in the other two panels, falling into the 10 percent range for large portions of the day. The differences, though large, are statistically significant only for two blocks of time that cover a little over two hours in the evening. In interpreting these results, one must keep in mind that the positive difference in the evening necessarily implies a negative difference at other times of the day. Thus the lack of statistical significance in the morning and afternoon does not mean that there is no effect. Rather, it arises because the effect is spread out over a larger portion of the day.

These results indicate that part-time employed mothers of pre-school-age children adjust their work schedule so that they work less during the day and more in the evening. This allows them to spend more time with their children throughout the day so that their enriching childcare time is not concentrated in the evening.

My analysis has largely ignored fathers, although the regression equations did include controls for the father's employment status and whether he worked full or part time. Ideally, I would like to be able to say something about the interaction of mothers' and fathers' work time. This type of analysis is impossible, because the ATUS collects data from only one household member. However, because the vast majority of these husbands work full time and full-time 
employed men work mostly on weekdays, I can make some inferences about how fathers’ work schedules affect when their wives work. ${ }^{29}$

Table 3 shows how women's work time is distributed across weekdays and weekends. Full-time employed women do most of their work on weekdays and there is very little variation by presence and age of children. About 33 of the 35 hours they work per week are worked on weekdays.

There is more variation among part-time employed women in both the number of hours worked per week and in the percent of that time that is worked on weekdays. The mothers of 0-4 year olds work the fewest hours per week, but work the most hours on weekends. Of the 16.5 hours that they work per week, 2.4 (14 percent) are worked on weekends. The mothers of 5-9 year olds work the most hours per week (20.0 hours), but work the fewest hours on weekends (1.0 hours or 5 percent of all hours). The mothers of 10-17 year olds fall between, working about 7 percent of their hours on weekends. Thus, the mothers of school-age children appear to be concentrating their work time on weekdays (school days), whereas the mothers of pre-schoolage children appear to work more on days when their husbands are likely to be available for childcare.

Given that the part-time employed mothers of school-age children work nearly all of their hours on weekdays, we might also expect them to shift their work hours to times when their children are in school. To examine this, I restricted the sample to days when school is in session (Sept. $15^{\text {th }}-$ Dec. $15^{\text {th }}$ and Jan. $15^{\text {th }}-$ May $15^{\text {th }}$ ) and calculated the fraction of total hours worked during school hours (9am - 3pm on weekdays). As a point of reference, full-time employed women (regardless of presence and age of children) and part-time employed non-mothers

\footnotetext{
${ }^{29}$ In 2006, about 88 percent of employed married men worked full time. Full-time employed men worked 5.1 days per week on average. Of those, 4.4 days ( 86 percent of workdays) were weekdays and 0.7 (14 percent) were weekend days or holidays.
} 
worked about 55 percent of their total weekly hours during school hours. Part-time employed mothers of school-age children worked most of their total weekly work hours—a little over 60 percent—during school hours. In contrast, part-time employed mothers of 0-4 year olds worked only 43 percent of their total weekly hours during school hours.

All of these results strongly suggest that one of the reasons that mothers of pre-schoolage children work part time is to have the flexibility to schedule work in order to spend time with their children throughout the day. For the mothers of school-age children, part-time employment allows them to work when their children are in school. The results also suggest that the greater ability to choose when they work is one of the attributes that makes part-time work desirable to working mothers. This explanation is consistent with the results of Ichino and Sanz de Galdeano (2005), who find that the availability of part-time jobs and flexible employment arrangements is a more important determinant of maternal employment rates than the availability of formal childcare facilities. Their research suggests that many of these part-time employed mothers would choose not to work, rather than work full time, if part-time jobs were not available.

\section{Summary and Conclusions}

The time that parents spend in enriching childcare activities is an important parental input to child development, and some recent studies have found that maternal employment can negatively affect child outcomes. An extensive literature has examined the effect of maternal employment on childcare time. Most of this literature has focused on the amount of time parents spend with their children, but has largely ignored when that time is spent.

The theoretical model predicts that mothers will want to spend more time in enriching childcare activities at times of day when those activities are the most productive. Psychological research on circadian rhythms suggests that early in the day is the best time for enriching 
childcare, but the productivity of enriching childcare time also depends on the mother's time-ofday preferences.

Focusing on mothers of pre-school-age children (ages 0-4), I found that enriching childcare activities are distributed fairly evenly over the day for employed mothers on their nonwork days and for non-employed mothers. This implies that the productivity of this time is about the same at all times of day and that, because the enriching childcare production function exhibits diminishing marginal productivity, the total value of enriching childcare time is maximized when that time is evenly distributed throughout the day.

On workdays, full-time employed mothers of 0-4 year olds shift much of the time spent in enriching childcare to the evenings. In contrast, the distribution of enriching childcare time for part-time employed mothers on their workdays looks much like the distributions for nonwork days. Thus, it appears that, while part-time employment affects the amount of time that mothers spend doing enriching childcare, it does not have a large effect on when that care is done.

I quantified the extent of this shifting of enriching childcare time using a dissimilarity index. Full-time employed mothers of pre-school age children would have to reschedule about 40 percent of enriching childcare time on workdays, compared to only 18 percent for part-time employed mothers, to make the workday distribution the same as the distribution for nonemployed mothers. This translates to 71 minutes per week for full-time employed mothers, compared to 30 minute for part timers.

Turning to the timing of employment, I found evidence that part-time employed mothers adjust their schedule so that they can spend time with their children throughout the day. Compared to employed women who are not parents, the preferred control group, the mothers of 0-4 year-olds are 18 percent (10 percentage points) less likely to be working in the morning and 
early afternoon. In contrast, the difference in timing between full-time employed mother of 0-4 year-old children and other full-time employed women is small, and there is no evidence that full-time employed mothers of 0-4 year olds adjust their schedules to spend more time with their children during the day.

These results suggest that mothers who work part time do so not only to spend more time with their children, but also to increase the value of that time. And they imply that looking only at the amount of time spent in enriching childcare activities understates the full impact of maternal employment on the enriching childcare for full-time employed mothers, but not for part timers.

My findings do not necessarily imply that the children of full-time employed mothers are worse off because of this shifting of enriching childcare time. These children presumably are in daycare or preschool, where they can participate in enriching activities with their teachers and other children throughout the day. As is the case when analyzing the effect of maternal employment on the amount of time mothers spend with their children, whether children are worse off depends on how substitutable this time is for maternal time. 


\section{References}

Allard, Mary Dorinda, Suzanne Bianchi, Jay Stewart, and Vanessa Wight (2007) "Comparing Childcare Measures in the ATUS and Earlier Time-Diary Studies.” Monthly Labor Review, May 2007, pp.27-36.

Bianchi, Suzanne (2000) "Maternal Employment and Time with Children: Dramatic Change or Surprising Continuity.” Demography 37, November 2000, pp. 139-154.

Bianchi, Suzanne (2006) “'What Gives’ When Mothers Are Employed? Parental Time Allocation in Dual Earner and Single Earner Two-Parent Families.” Unpublished manuscript, University of Maryland.

Bianchi, Suzanne, John Robinson, and Melissa Milke (2006) Changing Rythms of American Family Life, Russell Sage Foundation, New York.

Connolly, Marie (2008) "Here Comes the Rain Again: Weather and the Intertemporal Substitution of Leisure.” Journal of Labor Economics 26(1), January 2008, pp. 73-100.

Craig, Lyn (2006) "Where Do They Find the Time? Analysis of How Parents Shift and Squeeze Their Time around Work and Child Care.” The Levy Economics Institute Working Paper 439.

Frazis, Harley and Jay Stewart (2007) "Where Does the Time Go? Concepts and Measurement in the American Time Use Survey.” In Hard to Measure Goods and Services: Essays in Memory of Zvi Griliches, Ernst Berndt and Charles Hulten, eds., NBER Studies in Income and Wealth, University of Chicago Press, 2007. )

Hamermesh, Daniel S. (2002) “Timing, togetherness, and time windfalls.” Journal of Population Economics 15, pp. 601-623.

Hamermesh, Daniel S. (2005) “Routine.” European Economic Review 49(1) ,January 2005, pp. 29-53.

Hamermesh, Daniel S. and Stephen Donald “The Time and Timing Costs of Market Work.” NBER Working Paper 13127, May 2007.

Hamermesh, Daniel S., Caitlin Knowles, and Mark L. Pocock (2008) "Cues for Coordination: Light, Longitude, and Letterman.” Journal of Labor Economics 26(2), April 2008, pp. 223-246.

Hamermesh, Daniel S., Harley Frazis, and Jay Stewart (2005) "Data Watch: The American Time Use Survey.” Journal of Economic Perspectives 19(1), Winter 2005, pp. 221-232.

Hasher, Lynn, David Goldstein, and Cynthia P. May (2005) “It’s About Time: Circadian Rhythms, Memory, and Aging." In Human Learning and Memory: Advances in Theory and Application, ed. by C. Izawa and N. Ohta. Kansas: Lawrence Erlbaum Associates.

Ichino, Andrea and Anna Sanz de Galdeano (2005) "Reconciling Motherhood and Work: Evidence from Time-Use Data in Three Countries.” In The Economics of Time Use, ed. by D. Hamermesh and G.A. Pfann. Elsevier B.V., pp. 263-288. 
Kim, Sunghan, Gwenden L. Dueker, Lynn Hasher, and David Goldstein (2002) “Children’s time of day preference: age, gender, and ethnic differences,” Personality and Individual Differences 33, pp. 1083-1090.

Paley, Irina (2006) “Right Place, Right Time: Parents’ Employment Schedules and the Allocation of Time to Children.” Unpublished manuscript, March 2005, Brown University.

Snyder, Thomas D., Sally A. Dillow, and Charlene M. Hoffman (2008) Digest of Education Statistics 2007, NCES 2008-022, National Center for Education Statistics, Institute of Education Sciences.

Stafford, Frank and W. Jean Yeung (2005) “The Distribution of Children’s Developmental Resources.” In The Economics of Time Use, ed. by D. Hamermesh and G.A. Pfann. Elsevier B.V., pp. 289-313.

Stewart, Jay (2006) “Assessing Alternative Indexes for Comparing Activity Profiles,” electronic International Journal of Time Use Research 3(1), August 2006, pp. 49-59.

Wickersham, Leandra (2006) “Time-of-Day Preference for Preschool-Aged Children,” Chrestomathy: Annual Review of Undergraduate Research, School of Humanities and Social Sciences, School of Languages, Cultures, and World Affairs, College of Charleston, Volume 5.

van Klaveren, Chris and Henriette Maassen van den Brink (2007) "Intra-household work time synchronization: togetherness or material benefits.” Social Indicators Research 84, pp. 39-52.

Winston, Gordon C. (1982) The Timing of Economic Activities. New York: Cambridge University Press. 
Table 1. Hours spent in childcare by mothers on their diary day, 2003-2007 ATUS annual averages

\begin{tabular}{|c|c|c|c|c|c|c|c|}
\hline & \multicolumn{3}{|c|}{ Employed full time } & \multicolumn{3}{|c|}{ Employed part time } & \multirow[b]{2}{*}{$\begin{array}{c}\text { Not } \\
\text { employed } \\
\text { (all days) }\end{array}$} \\
\hline & $\begin{array}{c}\text { Workdays } \\
\text { (away from } \\
\text { home) }\end{array}$ & $\begin{array}{c}\text { Nonwork } \\
\text { Days* }\end{array}$ & All Days & $\begin{array}{c}\text { Workdays } \\
\text { (away from } \\
\text { home) }\end{array}$ & $\begin{array}{c}\text { Nonwork } \\
\text { Days* }\end{array}$ & All Days & \\
\hline \multicolumn{8}{|c|}{ Mothers of 0-4 Year-Old Children } \\
\hline Childcare (with child < 5) & 2.0 & 3.5 & 2.6 & 2.5 & 4.1 & 3.5 & 4.0 \\
\hline Routine childcare & 0.9 & 1.9 & 1.3 & 1.3 & 1.9 & 1.7 & 1.9 \\
\hline Enriching childcare & 0.7 & 1.4 & 1.0 & 1.0 & 1.9 & 1.5 & 1.9 \\
\hline Other childcare & 0.4 & 0.2 & 0.3 & 0.3 & 0.3 & 0.3 & 0.3 \\
\hline Observations & 432 & 511 & 943 & 160 & 365 & 525 & 942 \\
\hline \multicolumn{8}{|c|}{ Mothers of 5-9 Year-Old Children } \\
\hline Childcare (with child 5-9) & 1.5 & 2.4 & 1.8 & 1.7 & 2.7 & 2.3 & 2.7 \\
\hline Routine childcare & 0.5 & 0.6 & 0.5 & 0.6 & 0.8 & 0.7 & 0.7 \\
\hline Enriching childcare & 0.7 & 1.4 & 0.9 & 0.7 & 1.5 & 1.1 & 1.6 \\
\hline Other childcare & 0.4 & 0.3 & 0.4 & 0.4 & 0.5 & 0.5 & 0.4 \\
\hline Observations & 298 & 299 & 597 & 99 & 227 & 326 & 370.0 \\
\hline \multicolumn{8}{|c|}{ Mothers of $10-17$ Year-Old Children } \\
\hline Childcare (with child 10-17) & 0.7 & 1.2 & 0.9 & 1.0 & 1.5 & 1.3 & 1.6 \\
\hline Routine childcare & 0.1 & 0.1 & 0.1 & 0.2 & 0.2 & 0.2 & 0.3 \\
\hline Enriching childcare & 0.4 & 0.9 & 0.6 & 0.5 & 0.8 & 0.7 & 1.0 \\
\hline Other childcare & 0.2 & 0.2 & 0.2 & 0.3 & 0.4 & 0.4 & 0.3 \\
\hline Observations & 935 & 961 & 1896 & 262 & 501 & 763 & 782 \\
\hline
\end{tabular}

* Includes days on which the respondent worked at home and did not work away from home. 
Figure 1: Distribution of Time Spent in Enriching Childcare by Mothers of 0-4 Year-Old Children

Full-Time Employed on Workdays

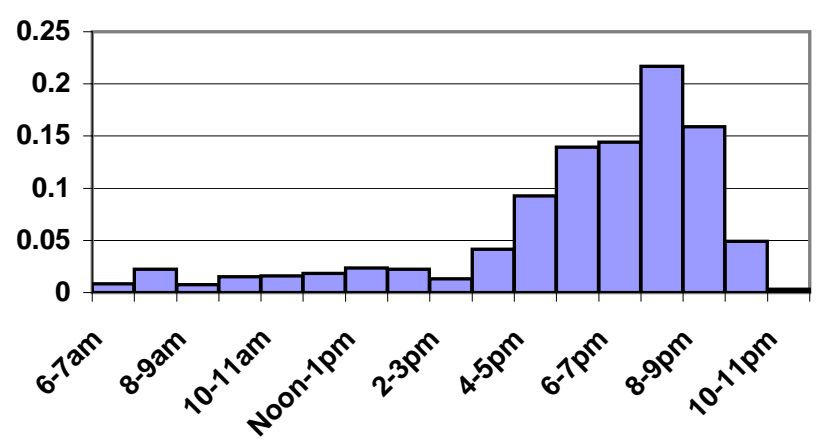

Part-Time Employed on Workdays

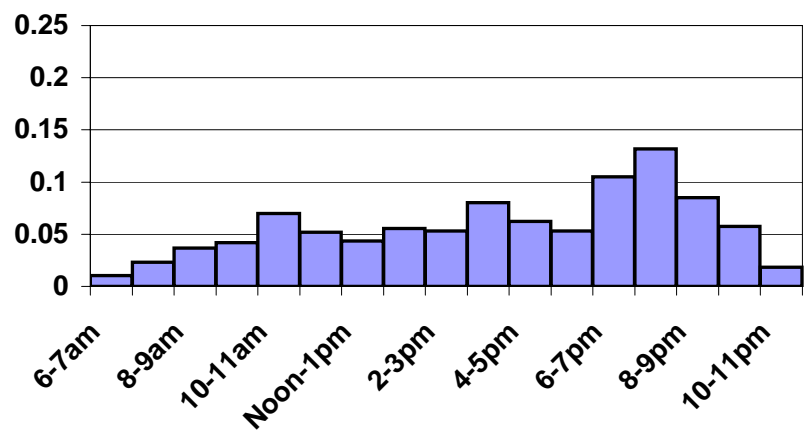

Full-Time Employed on Nonwork Days

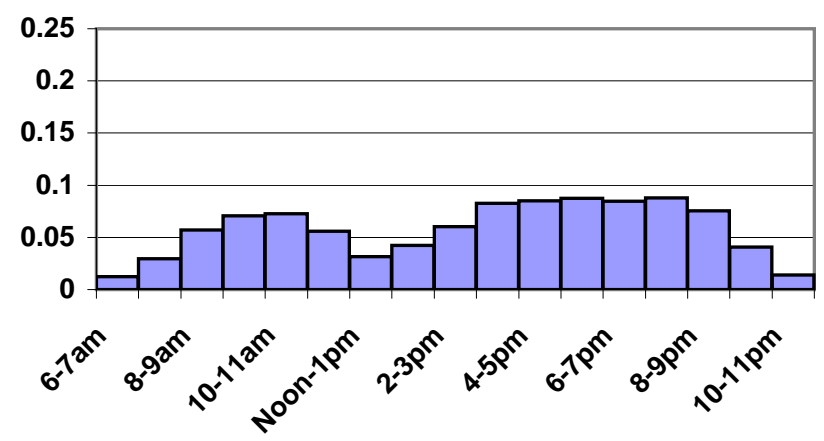

Part-Time Employed on Nonwork Days

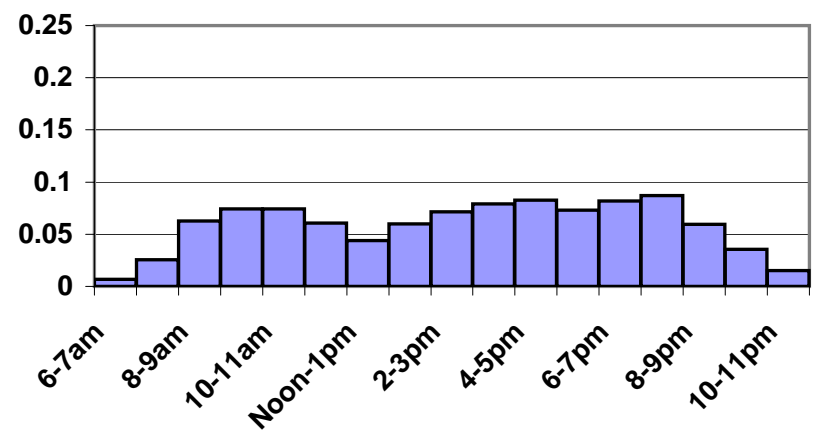

Non-Employed

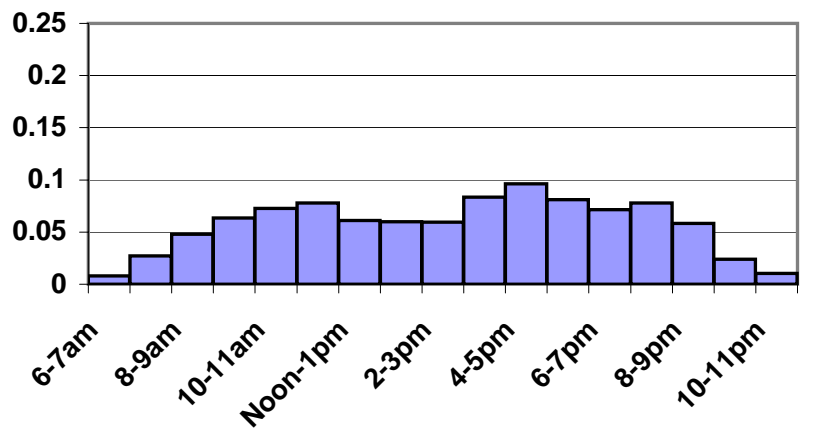


Table 2: Dissimilarity Index Comparisons of the Distribution of Enriching Childcare on Workdays and Nonwork Days - Mothers of 0-4 Year-Old Children

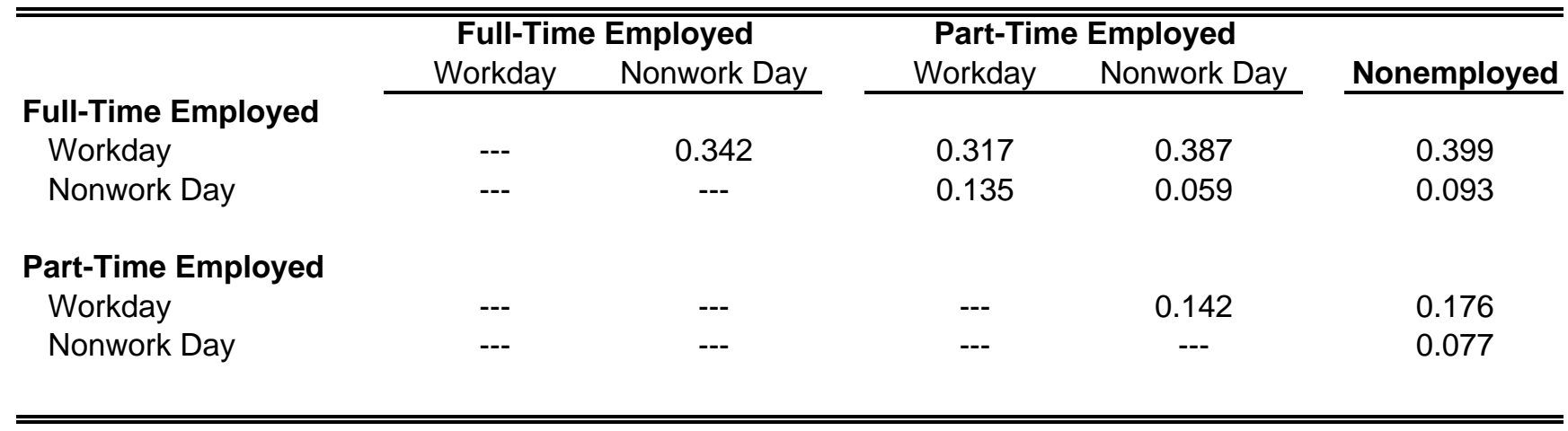


Figure 2: Distribution of Time Spent in Enriching Childcare by Mothers of 5-9 Year-Old Children

Full-Time Employed on Workdays

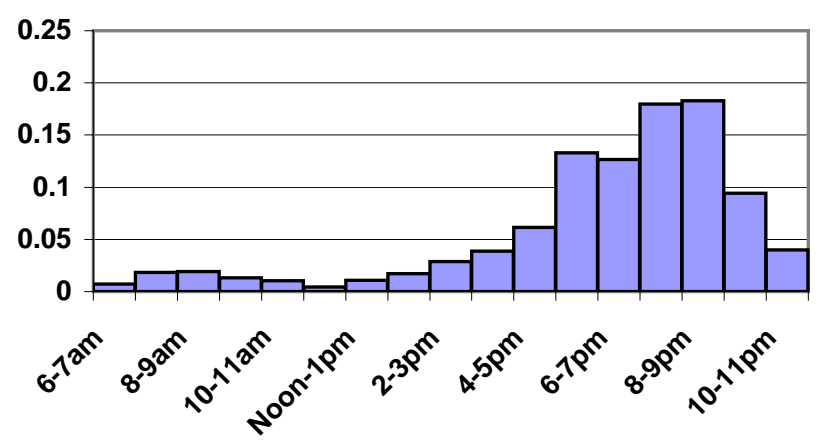

Part-Time Employed on Work Days

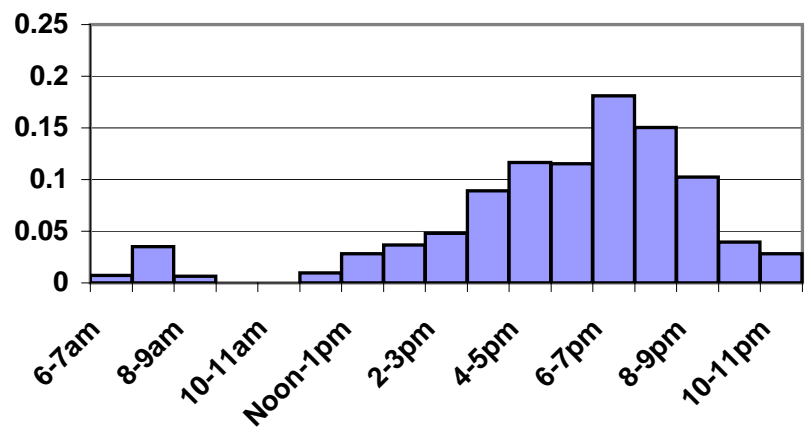

Full-Time Employed on Nonwork Days

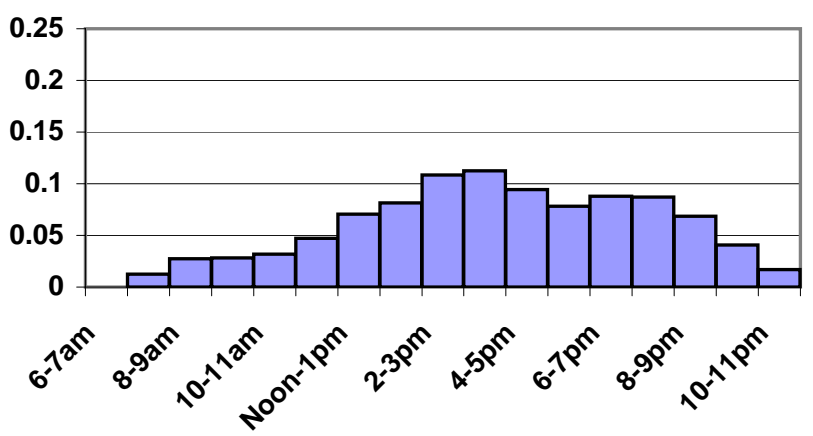

Part-Time Employed on Nonwork Days

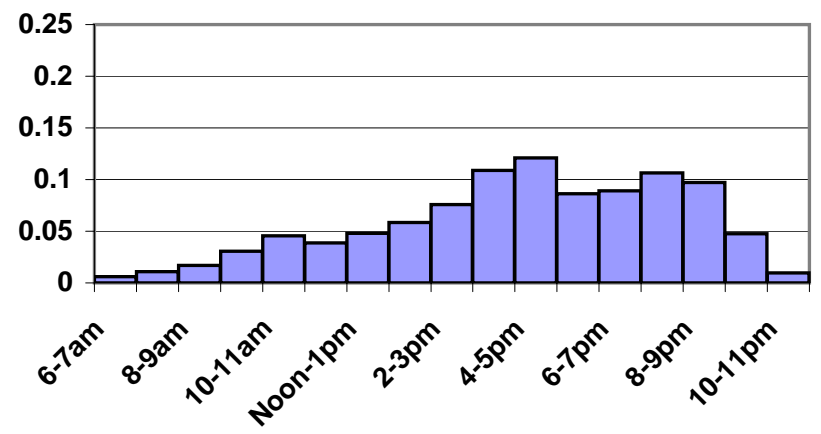

Non-employed

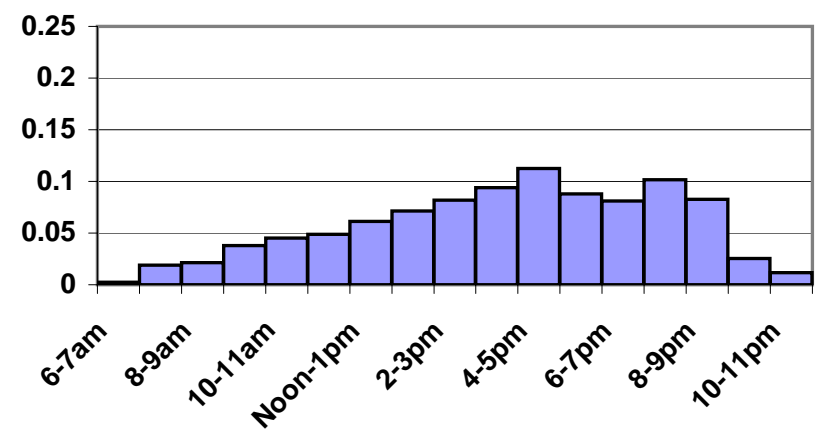


Figure 3: Difference in Percent of Full-Time Employed Mothers Working by Time of Day (Coefficient on Dummy for Presence of 0-4 Year-Old Children and $95 \%$ Confidence Interval)

Comparison to Mothers of 5-9 Year-Old Children

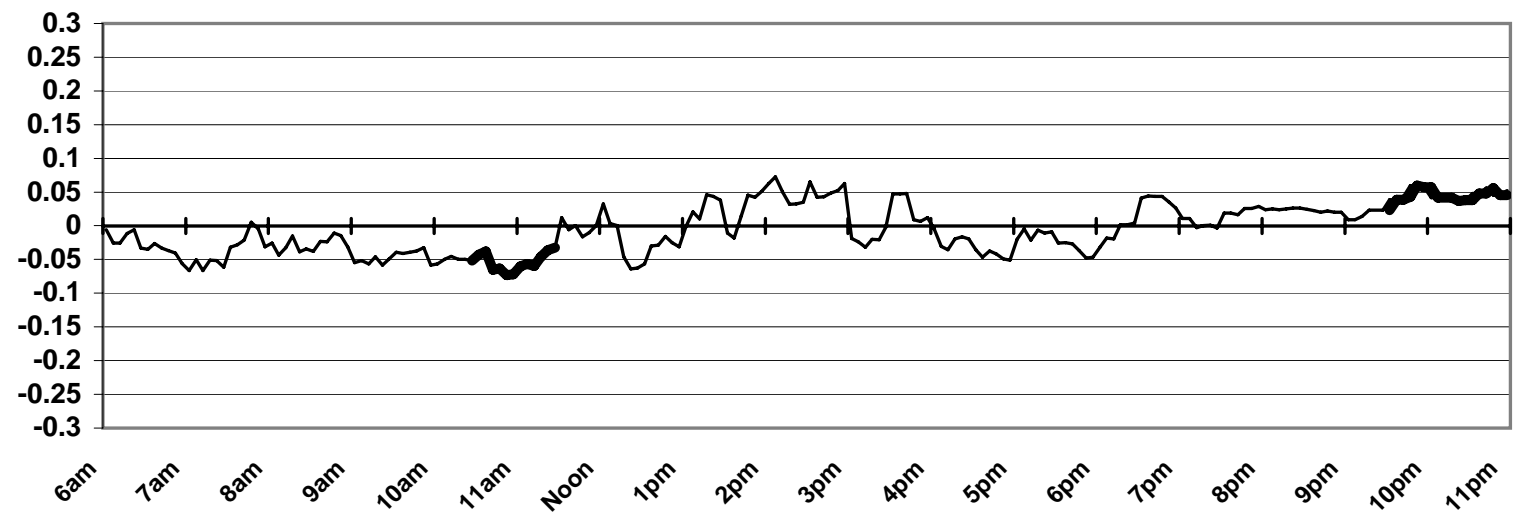

Comparison to Mothers of 10-17 Year Old Children

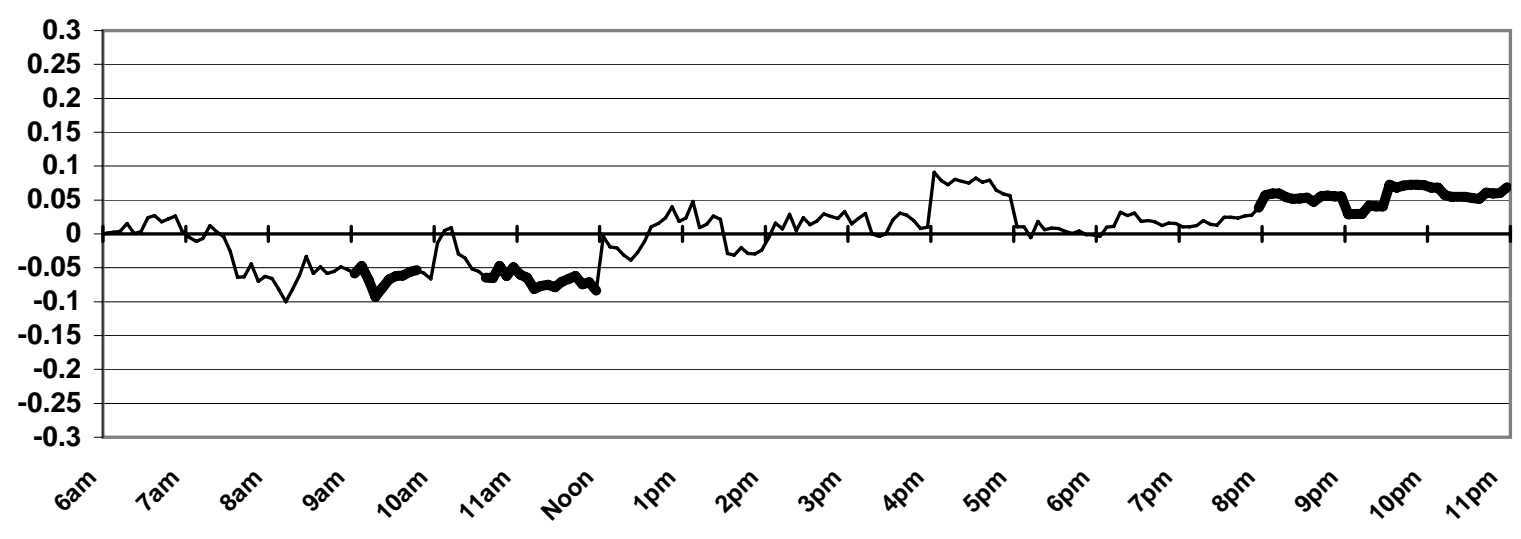

Comparison to Non-Parents

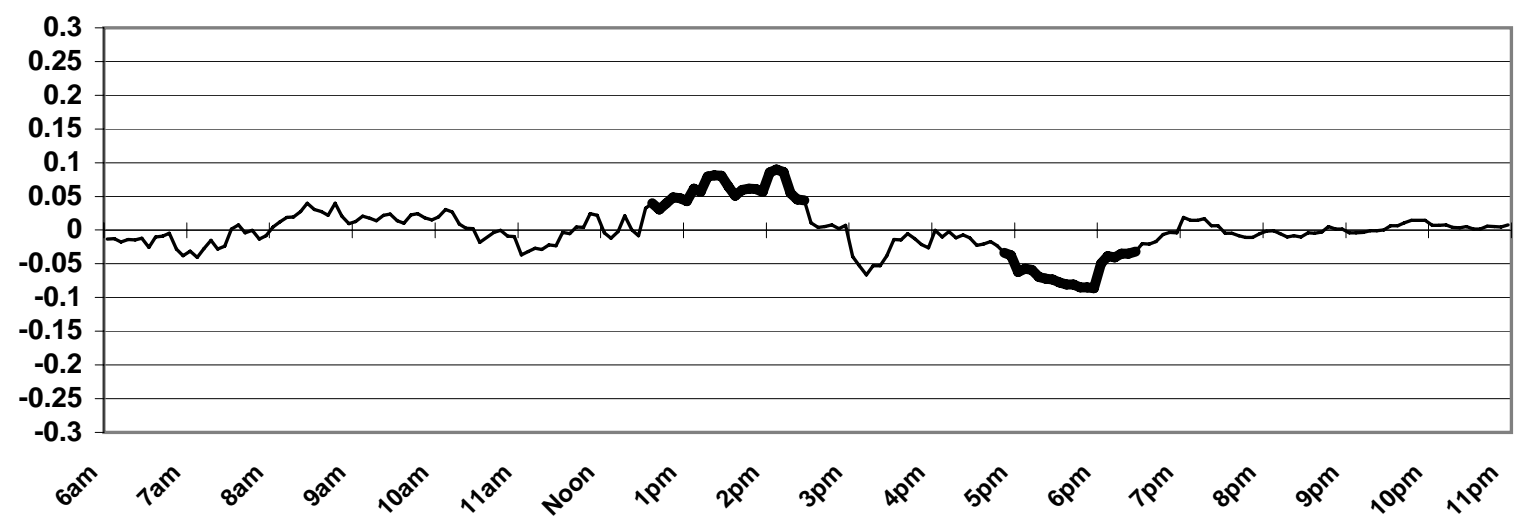


Figure: 4 Difference in Percent of Part-Time Employed Mothers Working by Time of Day (Coefficient on Dummy for Presence of 0-4 Year-Old Children and $95 \%$ Confidence Interval)

\section{Comparison to Mothers of 5-9 Year-Old Children}

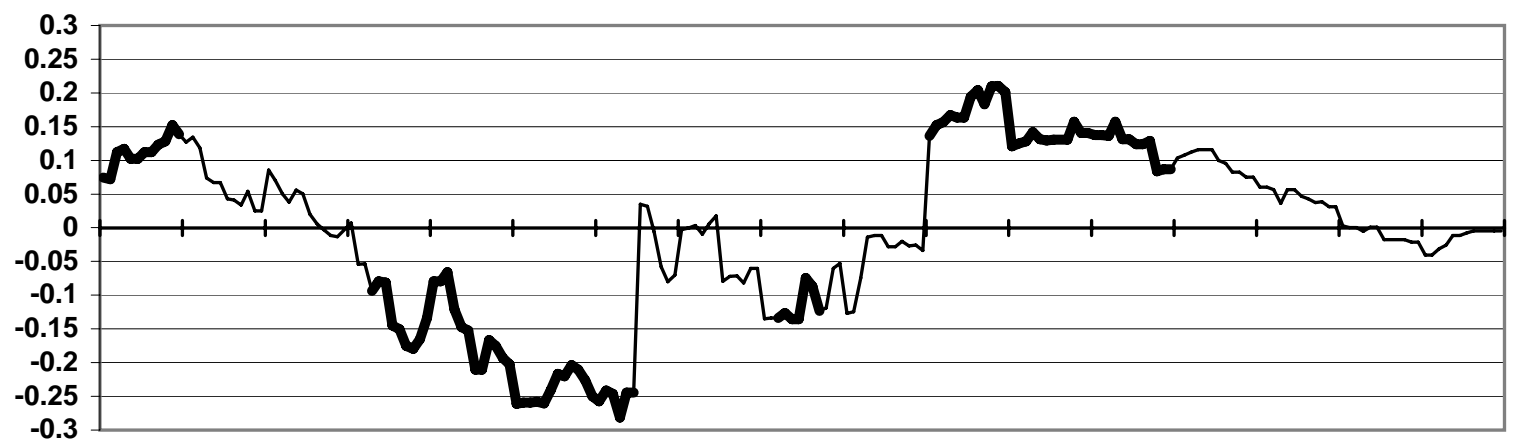

6 की

Comparison to Mothers of 10-17 Year-Old Children

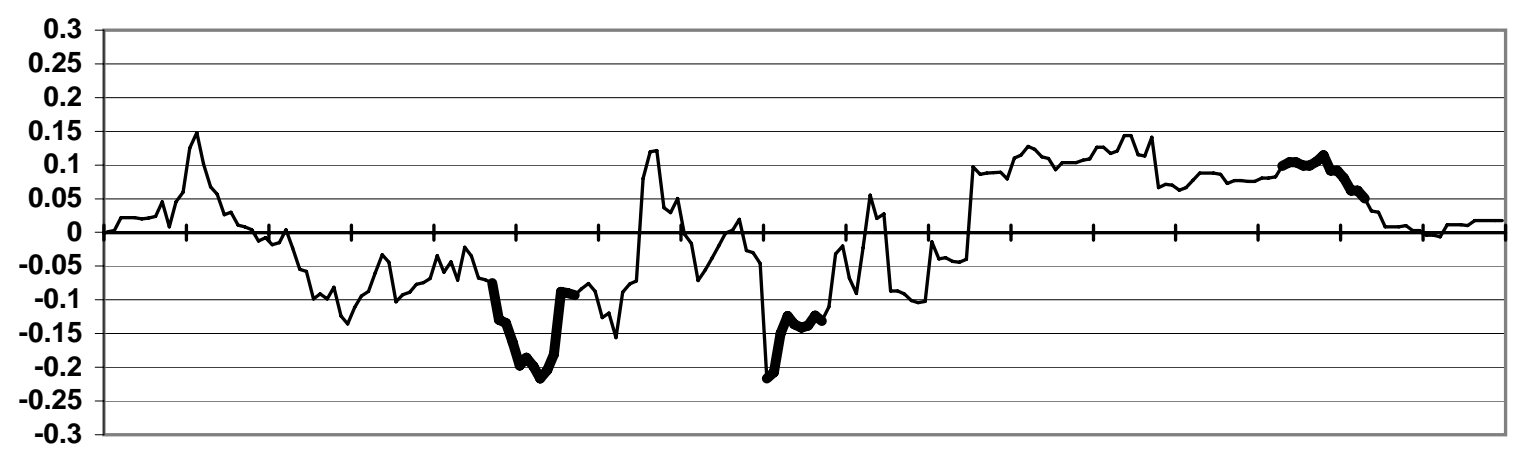

की

Comparison to Non-Parents

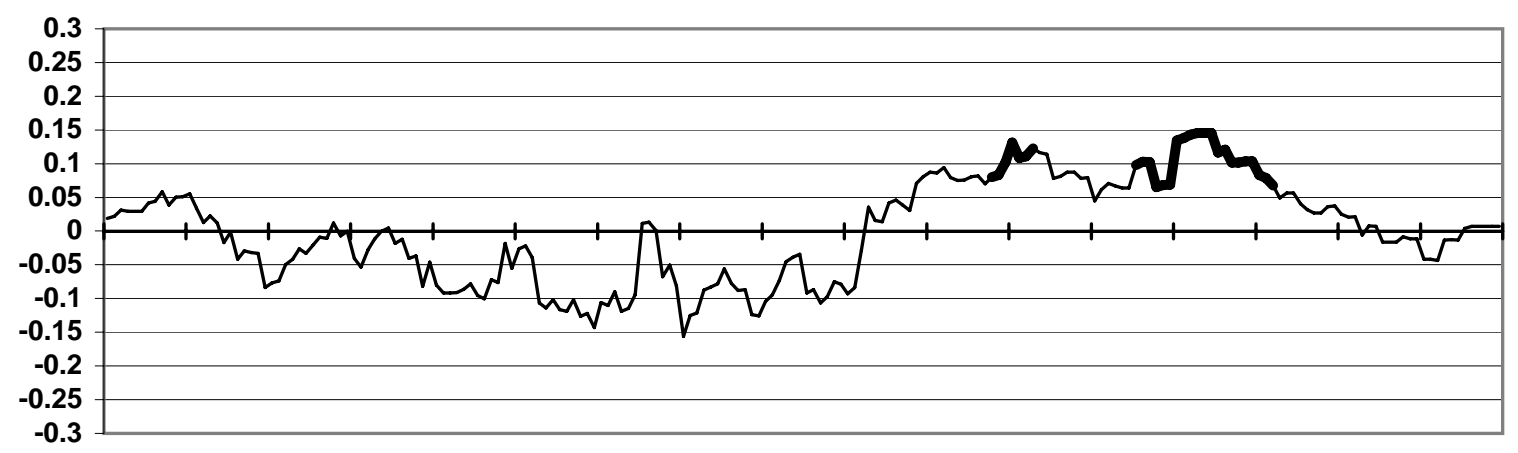

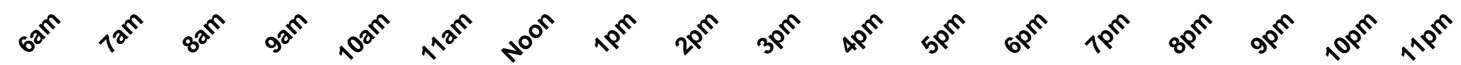


Table 3: Distribution of Work Between Weekdays and Weekends by Age of Children and Full-/Part-Time Status

\begin{tabular}{|c|c|c|c|c|c|c|c|c|c|}
\hline & \multicolumn{3}{|c|}{$\begin{array}{l}\text { Average Time Spent Working on } \\
\text { Diary Day }\end{array}$} & \multicolumn{3}{|c|}{ Fraction Working on Diary Day } & \multicolumn{3}{|c|}{$\begin{array}{l}\text { Average Time Spent Working on } \\
\text { Diary Day Conditional on Working }\end{array}$} \\
\hline & & Weekend & & & Veekend & & & Veekend & \\
\hline & Weekdays & Days & All Days & Weekdays & Days & All Days & Weekdays & Days & All Days \\
\hline \multicolumn{10}{|l|}{ Full-Time Employed } \\
\hline with 0-4 Year-Old Children & 6.5 & 1.0 & 5.0 & 83.6 & 16.9 & 64.6 & 7.8 & 5.9 & 7.3 \\
\hline with 5-9 Year-Old Children & 6.7 & 1.1 & 5.1 & 85.3 & 18.6 & 66.2 & 7.8 & 6.0 & 7.3 \\
\hline with 10-17 Year-Old Children & 6.6 & 1.1 & 5.0 & 82.5 & 18.5 & 64.2 & 8.0 & 6.0 & 7.4 \\
\hline Non Parents & 6.7 & 1.2 & 5.1 & 83.8 & 18.2 & 65.0 & 8.0 & 6.5 & 7.6 \\
\hline \multicolumn{10}{|l|}{ Part-Time Employed } \\
\hline with 0-4 Year-Old Children & 2.8 & 1.2 & 2.4 & 50.2 & 17.1 & 40.7 & 5.6 & 6.9 & 6.0 \\
\hline with 5-9 Year-Old Children & 3.8 & 0.5 & 2.9 & 62.0 & 7.1 & 46.3 & 6.2 & 6.8 & 6.3 \\
\hline with $10-17$ Year-Old Children & 3.4 & 0.7 & 2.6 & 58.6 & 14.8 & 46.0 & 5.8 & 4.6 & 5.5 \\
\hline Non Parents & 3.5 & 0.9 & 2.8 & 62.6 & 17.3 & 49.7 & 5.7 & 5.2 & 5.5 \\
\hline
\end{tabular}




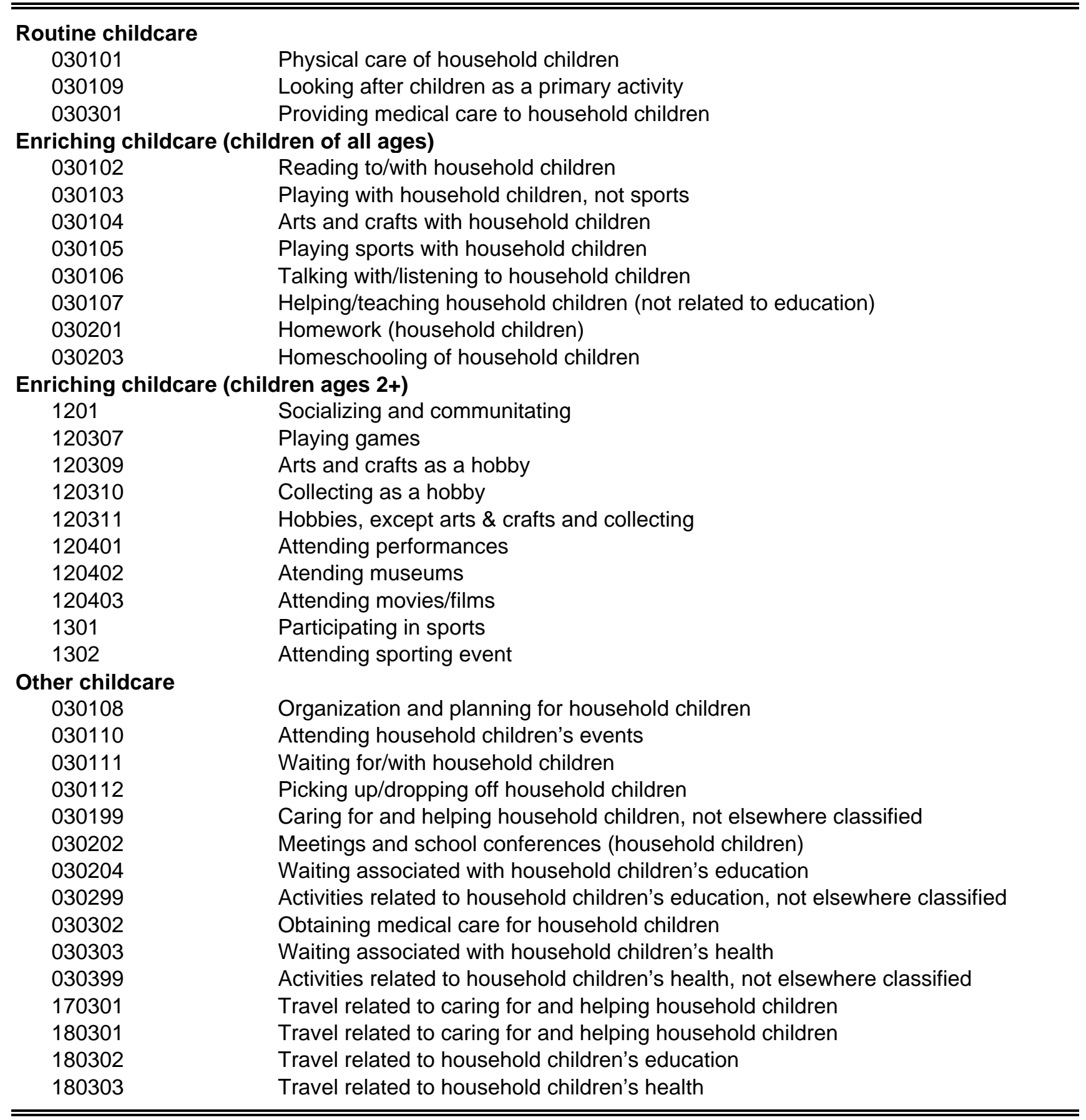

Note: A child must be present during enriching care activities. For children ages $2+$, enriching childcare includes leisure activities during which the child was present (see text for further details). 